\title{
The Role of Traditional Viticulture and Winemaking in the Development of the Geopark in Racha Region
}

\section{Tamar Chichinadze}

Scientist of Vakhushti Bagrationi Institute of Geography, Ivane Javakhishvili Tbilisi State University, Tbilisi, Georgia

Email: Tamar.chichinadze@tsu.ge, tamara.chichinadze@gmail.com

How to cite this paper: Chichinadze, T. (2021) The Role of Traditional Viticulture and Winemaking in the Development of the Geopark in Racha Region. Open Journal of Applied Sciences, 11, 1191-1199. https://doi.org/10.4236/ojapps.2021.1111089

Received: October 8, 2021

Accepted: November 14, 2021

Published: November 17, 2021

Copyright $\odot 2021$ by author(s) and Scientific Research Publishing Inc. This work is licensed under the Creative Commons Attribution International License (CC BY 4.0).

http://creativecommons.org/licenses/by/4.0/

\begin{abstract}
The main goal of my research is to introduce you to the Racha viticulture and wine-making territory. The region has a complex geological and geomorphological structure, which has greatly influenced the formation of relief formation, as well as the culture and traditions of the region. This is an area that meets all the requirements of a geopark, because a geopark is not just a geological area, and it is a connection between man and the earth at all levels. Exactly these connections are well identified in the field of this study. The presented viticulture microzone is located on both sides of the Rioni River, although the taste of grapes in the microzone varies from north to south, which does not depend on just one specific geographical component. Soil chemical composition, landscape characteristics, geological characteristics, terrain types, and more are important. Racha Viticulture - Wine Zone and its recognition play an important role in the development of geotourism. What is already creating new jobs is a new economic activity and an additional source of income, economic benefits. Also, the region is mountainous and characterized by severe depopulation. It is possible to limit emigration through research and development in this area.
\end{abstract}

\section{Keywords}

Viticulture-Winemaking, Tradition, Geotourism, GIS

\section{Introduction}

The study area is historic Racha, located in the northwestern part of Georgia. The territory and borders of historical Racha were constantly changing. Currently, Racha territory includes Oni and Ambrolauri municipalities and together 
with the other two municipalities (Tsageri and Lentekhi), forms the RachaLechkhumi-Kvemo Svaneti region. Racha covers an area of $2818 \mathrm{~km}^{2}$. Physically-geographically, Racha is located on the southern slopes of the Caucasus Mountains, mainly in the Rioni River basin. The northern border is the main ridge of the Caucasus from the peak of Phasi Mountain (west) to Zekar Pass (east), while the southern border is the Racha Range.

The territory of the region is characterized by mountainous terrain. The height of the region varies from $500-4500$ meters. The highest peak of Racha is Chanchakhi 4462 above sea level [1] (Figure 1).

This mountainous region has a rich cultural heritage. Here, all the buildings, household items, household tools, home interior, vintage or storage, grape picking, wine making are associated with rituals. The region has a rich tradition of viticulture and winemaking, which plays an important role in agriculture, as well as in terms of traditions and education.

\section{Methodology}

The research process was complex, consisting of materials obtained during field expeditions and the results of laboratory studies. Soil samples were taken at several locations during the expedition and geological and geomorphological surveys of the study area were conducted.

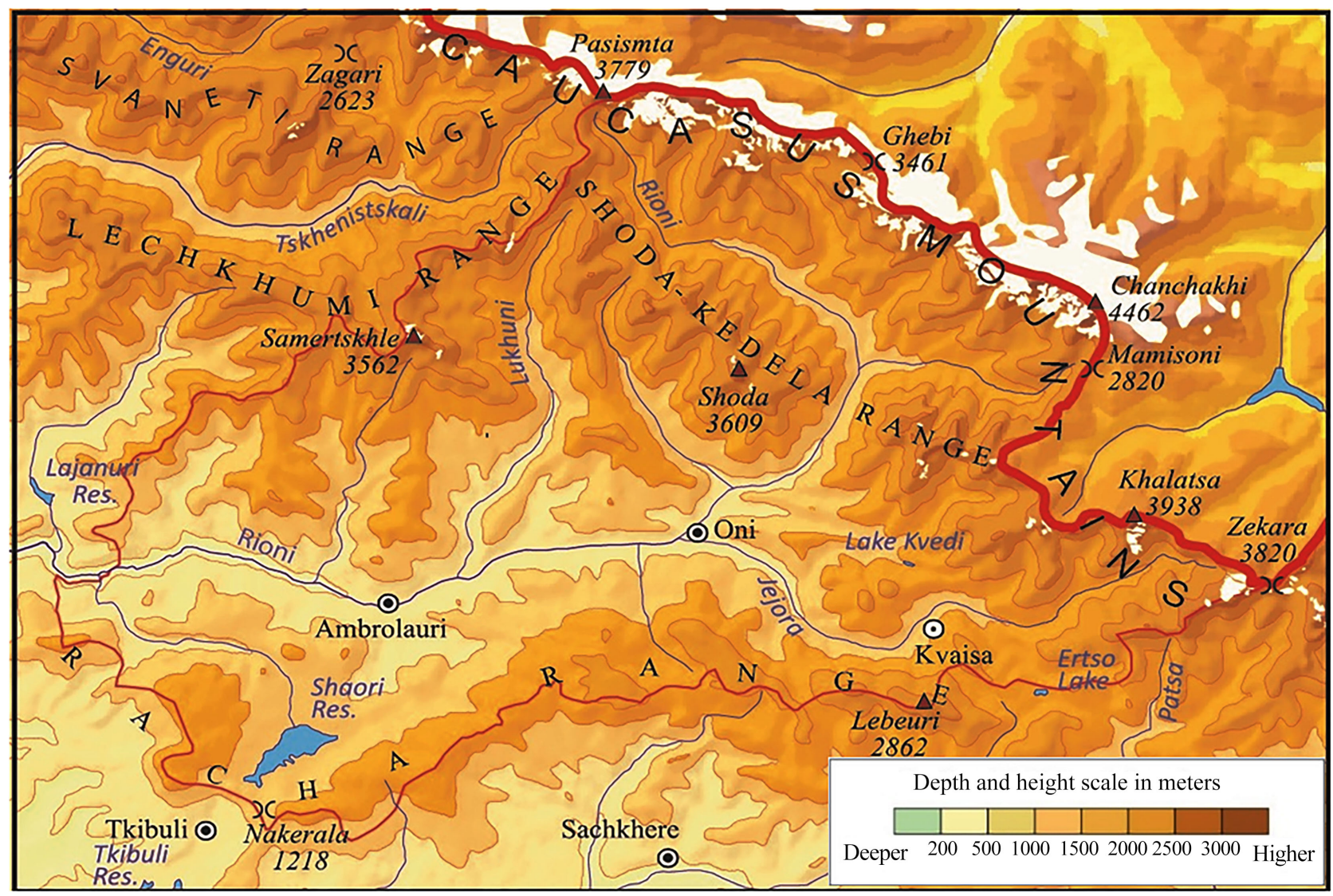

Figure 1. Physical map of Racha region, Georgia [2]. 
The Arc GIS program has compiled a digital geomorphological map of the Rioni Basin, in particular a viticultural distribution area showing relief forms and types, and identified risks. I compiled a soil map where I entered data on all types of soil, structure, and chemical composition that affect this sector of the farm.

Based on topographic maps, I have compiled viticulture distribution maps over several years to determine the probable causes of vineyard decline as well as the causes of extinct vine species.

Digital maps allowed me to determine the area of distribution of vineyards, the height of distribution, the microzones of vine varieties.

In the process of research, I used local scientific ampeological literature, which is mainly the scientific literature of the last century.

There was also contact with locals during the expedition. Respondents were mostly older people who gave us information about the vine, which is preserved only in the scientific literature today. They described the name, type, color, size, the village where this type was spread, the weight of the grapes.

\section{Results}

According to researchers, this field developed at the turn of the II and I millennia, as evidenced by the treasures studied as a result of various archaeological discoveries. After the conquest of Georgia, Russia showed great interest in Georgian viticulture and wine. These wonderful wines were given to Tsarist Russia free of charge [3].

Racha is not rich in land resources as it is a mountainous region. The main and most important fields of agriculture are viticulture and winemaking. The vineyards are mainly located in the lowlands, around the river Rioni and its tributaries, cultivated on slopes with soil-climatic conditions for the development of vine culture. However

Slopes are favorable for viticulture. Slope cultivation is also associated with great difficulties, as natural, untouched landscapes have long been destroyed here, therefore, as a result of human intervention, catastrophic processes are activated in nature: landslides, erosion, mud, resulting in declining agricultural land, which is why there is a strict migration of population. As can be seen from the map, viticulture is mainly spread in the Rioni River basin, terraces or surrounding areas (Figure 2).

It is characterized by a mountainous relief that develops in the Third Syncline Depression and extends almost from the Village Upper Ghvardia to Kvatskhuti (p. 24). On the right slope of the river there are nine terraces, among which are the lower, nearest terraces. Terraces on the left side of the river are not found at all. Such a difference on both sides of the river shows that the right side of the river, i.e. the northern part of the vineyard, is experiencing tectonic uplift, while the south is facing south.

On the right bank of the River Rioni, in the northern part of Mervin, there are three types of relief: 1) Medium-height mountain-valley, erosive, strongly segregated 


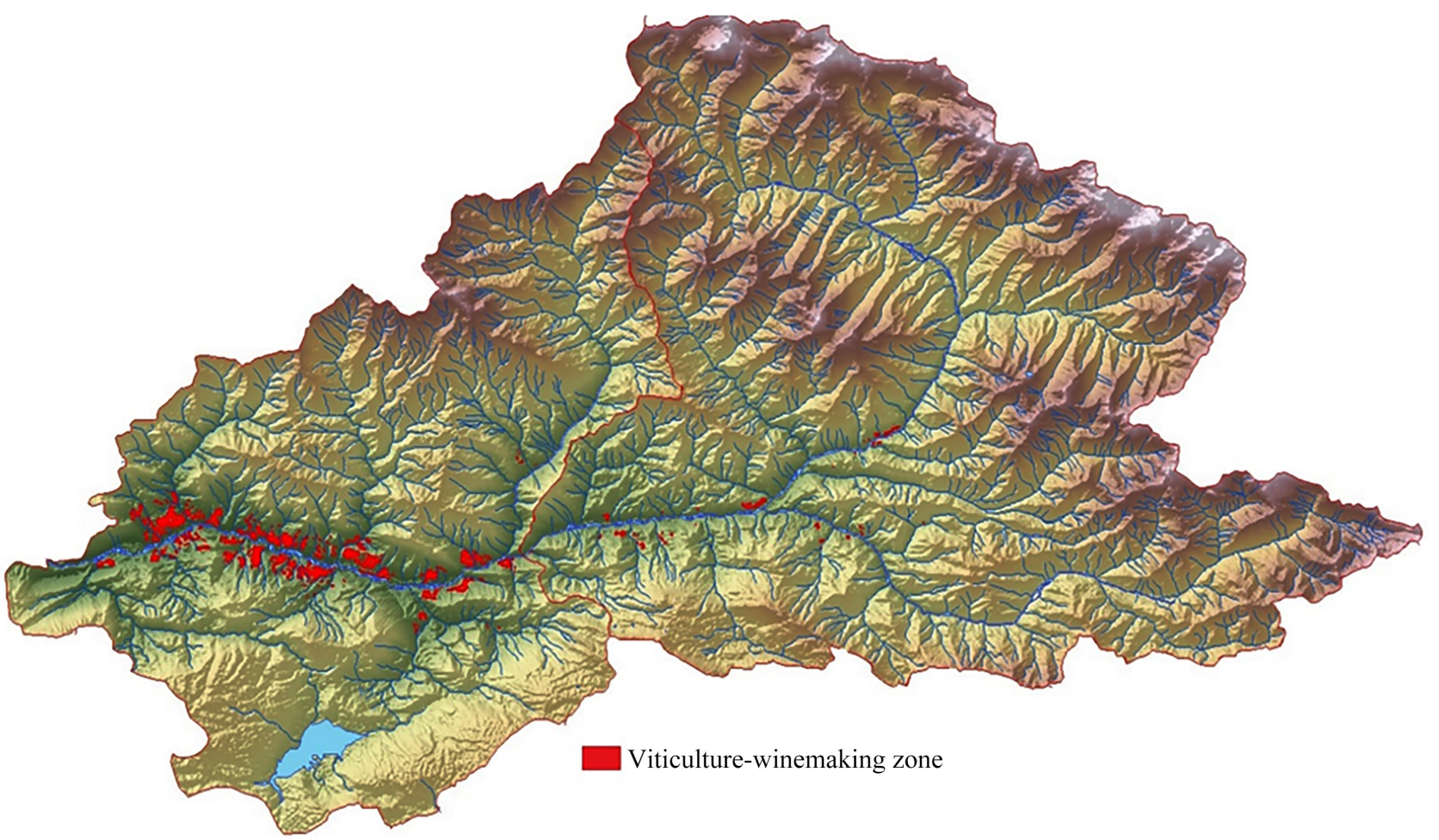

Figure 2. Viticulture-winemaking zone.

relief, developed in the Upper Lia shale massif. 2) Medium-height mountain-valley relief, developed on the basis of Bayo porphyritic limestones and chalk limestones. 3) Slope of the right terrace of the river Rioni, landslide-prone relief, produced by Oligocene, Middle and Lower Miocene, Sarmatian clays, sandstones, limestones, substation. In this part there are river terraces. For example, Dzirageuli and Sadmeli vineyards are planted on two terraces, Bostana village vineyards are planted on four terraces, Khvanchkara village is planted on one terrace, Kvemo Joshkha, villages in Chrebalo are planted on four terraces, vineyards are planted. The rivers in this section of the Rioni River are characterized by predominantly concentric valleys [4].

On the left bank of the Rioni River, in the southern part of viticulture, the following types of relief are distinguished: 1) Sonlkin depression of Racha-Lechkhumi mountainous, terraced landslide relief, developed on the third and fourth clay substrates, marls, limestones. Canyon-like valleys are common; 2) lowland mountainous, erosive-karstic relief, with deep canyon valleys, upper Cretaceous limestones and marls are developed on the substrate [5] (Figure 3).

Soils are subject to natural landscape zoning. Typical alluvial soils of the floodplain are found in the floodplains of the Rioni River. There are some soils in the viticulture zone: 1) Raw Hummus Calcareous Soils (Leptosols Rendzic) Raw Hummus Calcareous soils are characterized by a granular structure. The thickness of the soil varies from 40 to $60 \mathrm{~cm}$, which is transformed into deeper layers into limestone fragments of solid rocks. These types of soil contain heavy loam or large loam which is good for vineyard. At this stage only a relatively 
complete analysis of this type of soil has been carried out. Soil samples showed that the soil $\mathrm{pH}$ is very high at 7.8 ; The average concentration of calcium carbonate is $20 \%$; Soil salinity (EC in micro Siemens $/ \mathrm{cm}$ ) 65.2; Fe - 12.\% in soil; In $\mathrm{Al}$ soil - $12 . \%$.

2) Yellow brown forest (Stagnic, Mollic, Ferric Luvisols); 3) Brown forest Soils (Cambisols Eutric and Cambisols Dystric) [1] (Figure 4).

\section{Geomorphological structure of the viticulture area}

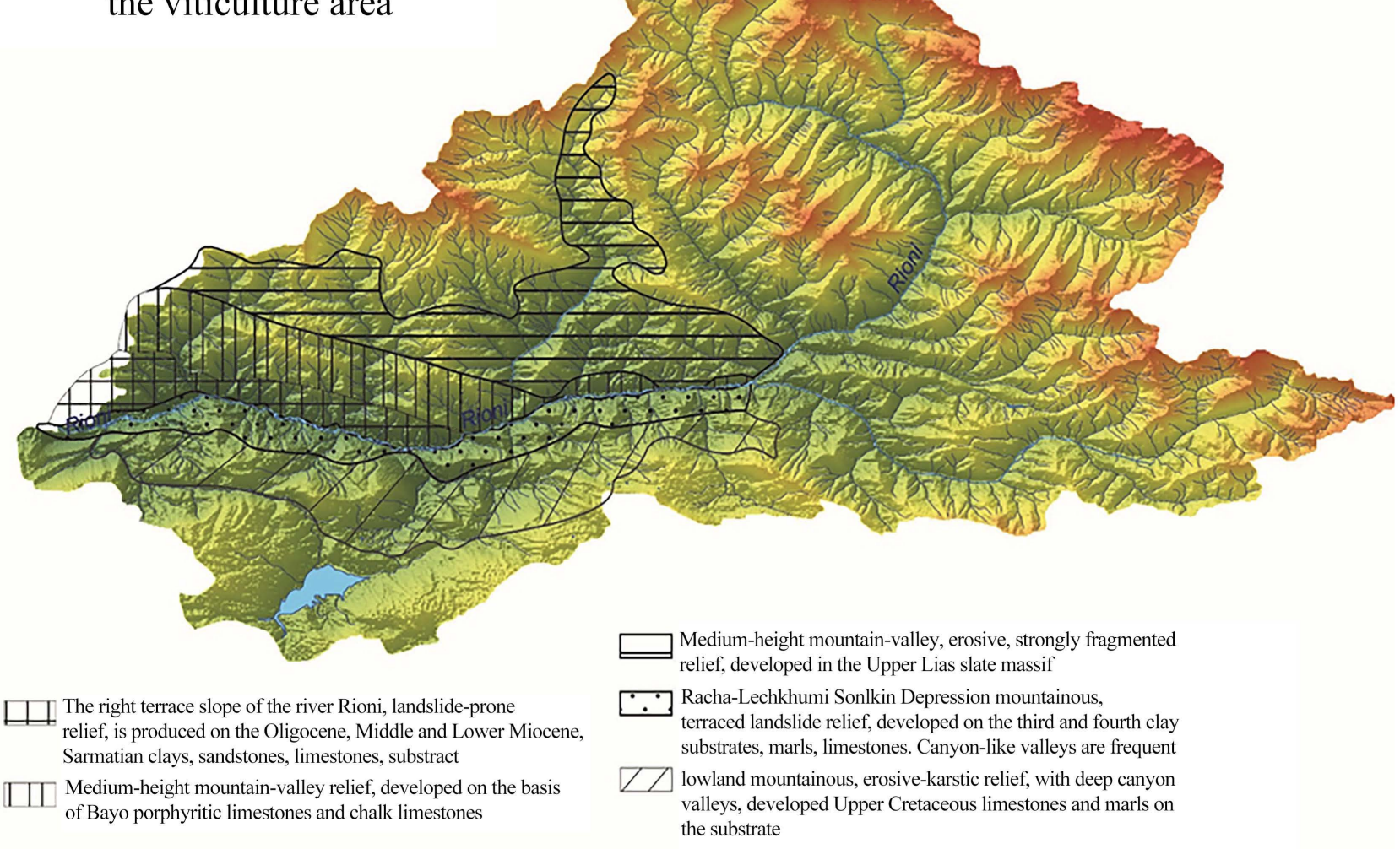

Figure 3. Geomorphological strucure of the viticulture area.

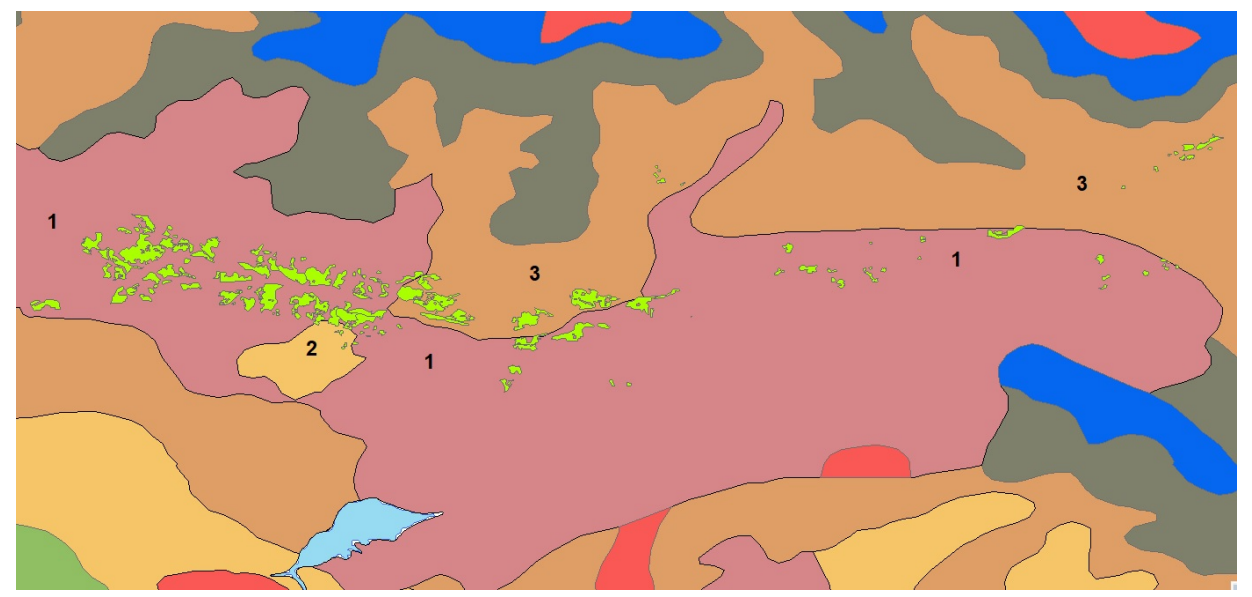

Figure 4. Map of soils of viticulture zone: 1) Raw Hummus Calcareous Soils (Leptosols Rendzic); 2) Yellow brown forest (Stagnic, Mollic, Ferric Luvisols); 3) Brown forest Soils (Cambisols Eutric and Cambisols Dystric) [2]. 
As we can see, this part of viticulture is favorable in terms of soil and climate, but is a constant threat due to intense landslides and erosion processes. Due to these processes, many local vine species are no longer found today.

The area of vineyards in Racha was constantly changing due to climate change, hisorical events and migration. Today the knowledge of vine cultivation is forgotten according to the ripening periods of the grapes. It is known that such a tradition existed in Racha, when there were grape growing zones in the region according to ripeness, quality and taste. Many varieties of grapes have also become extinct and local traditional grapes have been replaced by non-local varieties. Today it is difficult to talk about the exact area of vineyards in Old Racha, its location and distribution.

The only thing we can talk about is the exact fields of viticulture and winemaking of the recent past. As a result of deciphering the topographic maps, we can conclude that vines have been grown almost everywhere in Ambrolauri municipality, both in the villages and outside the villages. There are vineyards near almost every garden. Vineyards are cultivated in Kvemo Racha from 450 meters to 1100 meters (village Likheti), and Khvanchkara microzone from 450 to 650 meters. The upper belt of vineyards in Upper Racha is 1100 - $1200 \mathrm{~m}$ above sea level.

Scientists distinguish three viticulture zones in Racha: villages with vineyards (vines grow everywhere, both in the village and its surroundings), villages with semi-vineyards (cultivated only in villages and often characterized by low yields), villages without vineyards (where vines grow), except rare Cases and vineyards in other villages).

For the first time, Professor Modebadze saw wine microzones according to taste and quality: Kvemo (right side of Rioni - production of naturally sweet wines and white table wines) and Zemo Racha (also white and red table wines).

There are about 60 local grape varieties in Racha. According to old data, many species of grapes are extinct in the region. We propose a fragment of a database of viticulture-winemaking geo-information maps (data are collected in expeditions) (Table 1$)$.

Tsolikauri, a variety imported to Racha, which was cultivated after the Second World War. The reason was weather resistance. Massive development of Tsolikauri brought other local varieties to the brink of extinction in Racha, such as: Noshrio, Kvira, Shavruani, Shamella, Samachria, Shamaga, Tsitelouri, Dondghlabi, Chrochina, Atenura (imported from Shida Kartli), Mzhavela, Machanuri, Mokaturi, Avasankharkhva (Butku, Sakmevela, Samchatria, Janguli, Mokaturi, Kototskhovela, Kikatauri, Datsseula and others [3].

One of the main traditional wine zones is "Khvanchkara Microzone", where the famous Khvanchkara wine grapes are brewed, spread from Aski water and include the villages: First Tola, Second Tola, Khvanchkara, Patara Chorjo, Didi Chorjo, Bostana and Ghviara. What 1 . According to Pruidze, from the above we can also add upper and lower joshka, lower chkvish and sand. At the same time, 
the highest quality khanchkara material comes from the first equal and the second equal, khvanchkara, big chorjo and and small chorjo. In these five villages he prefers Patara Chorjo, where the grapes Alexandroula and Rachuli Tetra are grown.

Table 1. Former areas of distribution of grape varieties.

\begin{tabular}{|c|c|c|}
\hline Municipality & Village & Extinct grape variety \\
\hline Ambrolauri & Kedisubani & Bakhva, Mobazuri-Obazuri, Prangula \\
\hline Ambrolauri & Chrebalo & Berbesho \\
\hline Ambrolauri & Sakecia & Bulghva \\
\hline Ambrolauri & Tkhomi & Tkhmoruli \\
\hline Ambrolauri & Baji & Kampala \\
\hline Ambrolauri & Abanoeti & Kirtsitela, Peruani, Prangula, Beraula \\
\hline Ambrolauri & Tola & Kotskhana, Sadmeluri \\
\hline Ambrolauri & Mukhli & Kundza \\
\hline Ambrolauri & Likheti & Mskhviltvala, Rko, Prangul \\
\hline Ambrolauri & Komandeli & Mskhviltvala \\
\hline Ambrolauri & Jvarisa & Okhtouri, Meliskuda \\
\hline Ambrolauri & Ghari & Otskhanuri (Enterid from Imereti region) \\
\hline Ambrolauri & Ojaleshi & Ambrolauri (Entered from Samegrelo) \\
\hline Ambrolauri & Tsesi & Rko, Old Alexandroula, Kartula \\
\hline Ambrolauri & Lachta & Rko \\
\hline Oni & Sheubi & Rko \\
\hline Ambrolauri & Ghari & Urishula \\
\hline Oni & & Perovani \\
\hline Oni & Ghebi & Verulashvi-Shoubani \\
\hline Oni & Tsola & Rikintula \\
\hline Ambrolauri & Bugeuli & Kornistvala, Tsiitskina \\
\hline Ambrolauri & Bostana & Kornistvala \\
\hline Ambrolauri & Znakva & Kornistvala \\
\hline Ambrolauri & Khotevi & Khoteura \\
\hline Ambrolauri & Ambrolauri & Goruli mtsvane (entered from Shida Kartli) \\
\hline Ambrolauri & Sori & Khrogi, Kartula \\
\hline Ambrolauri & Chala & khurkhala \\
\hline Ambrolauri & Banks of the Rioni River in almost every village & Kudurauli \\
\hline Ambrolauri & Sadmeli & Sadmeluri \\
\hline Ambrolauri & Khvanchkara & Labilauri, Sadmeluri \\
\hline Oni & Oni & Semilioni \\
\hline Ambrolauri & Chkvishi & Pashinaki \\
\hline Ambrolauri & Baji & Pashinaki \\
\hline
\end{tabular}


Today, "Sakipiano Center" is referred to as the Khvanchkara Microzone (Figure 3) and covers a wider area, in the village of Ambrolauri, in the villages of the Rioni River Basin: rule, Kvatskhuti, Sadmeli, Givari, Bostana, Didi Chorjo, Patara Chorjo, First Tola, Second Tola, Chrebalo, Chkhvishi, Joshkha, Kvishri, Gvvaria, Barrel, Ghadishi, Baji, Bugeuli, Saketsia, Jvari, Itsa, Krikhi, Akhalsopeli, Gori, Khimshi, Abanoeti above (400-7 above sea level). Khvanchkara microzone is located between the ridges. The main part of the vineyards is cultivated on a flat surface, near the river, in gardens, in the northern part of the Racha limestone ridge. Climatic-humid subtropical, characterized by moderately cold winters (average $0^{\circ}-1^{\circ}$ January) and hot summers (average temperatures $21^{\circ} \mathrm{C}$ $22^{\circ} \mathrm{C}$ in warm months, maximum $36^{\circ} \mathrm{C}-37^{\circ} \mathrm{C}$ ). The grapes will start technical maturity on September 25. The grapes are harvested from the second half of October.

Wine production Khvanchkara was founded by Dimitri Kipiani in the 80s of the XIX century. From the unique grape varieties "Alexandrouli" and "Mujuretuli" he presented an excellent semi-sweet red wine by the method of incomplete fermentation, which was then called "Kipiani wine". Dimitri Kipiani sent his wine to the Belgian city of Austin, where the European Wine Festival was held. Wine won the Golden Grand Prix. This was the greatest victory of Georgian winemaking and, in particular, Kipiani [6].

Wine making in Racha has its old tradition. A winery is a building or property that produces wine, or a business that is involved in winemaking, for example, a wine company. There is a cellar in Georgian. Almost every old house has its own old cellar. Due to the fact that Racha is a mountainous region, the wine was stored in closed cellars, as the building protects the wine from frost in winter and heat in summer [6].

\section{Conclusions}

As can be seen in the topic, viticulture is one of the most important economic sectors in the region, located on a complex geological and geomorphological terrain associated with a seismically active site. Because this area is characterized by landslides, erosions, it is necessary for people to have less impact on nature to avoid both natural and human damage. However, the area has favorable soil vegetation cover for viticulture. Also today many local grape species are extinct and we have only descriptive information about them; however, in this case, the extinction of the vine species is not related to the landslide; it is related to more difficult climatic conditions as some of the described grape species are no longer found in growing regions with harsh climates. Due to these harsh conditions, population migration is frequent.

In order to maintain the traditional mountain viticulture and winemaking, it is necessary to raise the world awareness about the region and to implement international level projects, such as a geopark, which will play an important role in stopping severe depopulation. 


\section{Acknowledgements}

This work is supported by Shota Rustaveli National Science Foundation (SRNSF) (No. PHDF-19-3671).

\section{Conflicts of Interest}

The author declares no conflicts of interest regarding the publication of this paper.

\section{References}

[1] Gobejishvili, R. (2000) Racha-Lechkhumi. Physical Geography, Part I, Geography of Georgia "Science", Georgia, Tbilisi, 255-257.

[2] Atlas of Georgia. (2018) Germany, Stuttgard, 6, 74. Scientific Atlas.

[3] Pruidze, L. (1974) Viticulture and Enology in Georgia. Georgia, 5, 11, 43.

[4] Nemanishvili, S. (1960) For the Geomorphology of the Northern Part of Kvemo Racha. Proceedings of the Vakhushti Bagrationi Institute of Geography, 12, 36-37.

[5] Changashvili, G. (1960) Geomorphological Essay of the Southern Part of Kvemo Racha. Proceedings of the Vakhushti Bagrationi Institute of Geography, 12, 55-56.

[6] http://khvanchkara.net 